\title{
Van A tot Z; de uitspraken van het Hof van Justitie betreffende homoseksuele asielzoekers
}

\author{
Mr. dr. K. Zwaan*
}

In de zaken $X, Y$ en $Z$ (C-199/12, C-200/12 en C-201/12) oordeelde het Hof van Justitie op 7 november 2013 dat homoseksuelen een bijzondere sociale groep vormen, van homoseksuele asielzoekers niet kan worden verlangd dat zij discretie betrachten en dat de enkele strafbaarstelling van homoseksualiteit onvoldoende is om gegronde vrees voor vervolging aannemelijk te achten.

Op 2 december 2014 beantwoordde het Hof van Justitie de vraag over de toets van de geloofwaardigheid van asielrelazen van homoseksuele asielzoekers in de zaken $A$, $B$ en $C$ (C-148/13, C-149/13 en C-150/13).

Het Hof van Justitie heeft in deze uitspraak een beperkt aantal problematische onderzoeksmethodes ter vaststelling van de geloofwaardigheid van homoseksualiteit verboden. De vraag naar de rechtmatigheid van een aantal andere methodes blijft bestaan. Het Hof van Justitie laat deze toets aan de nationale rechter, en oordeelt dat bij deze toets de eerbiediging van artikel 1 EU Grondrechtenhandvest (menselijke waardigheid) richtinggevend is.

Hvf 2 december 2014, gevoegde zaken C-148/13, C-149/13 en C-150/13, A, B en C, ECLI:EU:C: 2014:2406

Hvf 7 november 2013, gevoegde zaken C-199/12, C-200/12 en C- 201/12, X, Y en Z, ECLI:EU:C: 2013:720

\section{Inleiding en achtergrond}

De Afdeling bestuursrechtspraak van de Raad van State (hierna: ABRvS of Afdeling) heeft in een aantal zaken betreffende asielverzoeken van homoseksuelen met het oog op de toepassing van richtlijnen uit het Gemeen-

Mr. dr. K. (Karin) Zwaan is coördinator van het Centrum voor Migratierecht van de Radboud Universiteit Nijmegen schappelijk Europees Asielsysteem (GEAS) prejudiciële vragen gesteld. In de zaken $X, Y$ en $Z$ (HvJ 7 november 2013, gevoegde zaken C-199/12, C-200/12 en C-201/12) deed het Hof van Justitie in november 2013 uitspraak. X, Y en Z uit respectievelijk Oeganda, Sierra Leone en Senegal vroegen in Nederland asiel. Zij stelden dat zij in hun landen van herkomst voor vervolging hadden te vrezen vanwege hun homoseksualiteit. De minister van Immigratie, Asiel en Integratie ${ }^{1}$ twijfelde niet aan hun homoseksualiteit en betwistte evenmin dat homoseksualiteit strafbaar is in Sierra Leone, Oeganda en Senegal. Als uitgangspunt gold dat seksuele geaardheid niet verborgen hoeft te worden gehouden, maar het was niet nodig dat $\mathrm{X}, \mathrm{Y}$ en $\mathrm{Z}$ er openlijk uiting aan zouden moeten kunnen geven op dezelfde wijze als in Nederland gebruikelijk is, aldus de minister.

In het arrest $X, Y$ en $Z$ oordeelde het Hof van Justitie dat homoseksuelen een bijzondere sociale groep vormen in de zin van de Definitierichtlijn ${ }^{2}$ indien in het land van herkomst strafrechtelijke bepalingen bestaan die specifiek zien op strafbaarstelling van homoseksualiteit. De enkele strafbaarstelling van homoseksualiteit is, aldus het Hof van Justitie, onvoldoende om gegronde vrees voor vervolging aannemelijk te achten. Dit is pas het geval als daadwerkelijk gevangenisstraf vanwege homoseksuele gedragingen wordt opgelegd. Ook bepaalde het Hof van Justitie dat niet van iemand kan worden verwacht dat hij zijn homoseksualiteit in het land van herkomst verbergt of zich terughoudend opstelt om zo

1. Op dat moment de verantwoordelijk bewindspersoon, nu is dit de staatssecretaris van Veiligheid en Justitie.

2. Richtlijn 2004/83/EG van 29 april 2004 inzake minimumnormen voor de erkenning van onderdanen van derde landen en staatlozen als vluchteling of als persoon die anderszins internationale bescherming behoeft, en de inhoud van de verleende bescherming, PbEU 2004, L 304/12; nu geldend is Richtlijn 2011/95/EU van 13 december 2011 inzake normen voor de erkenning van onderdanen van derde landen of staatlozen als personen die internationale bescherming genieten, voor een uniforme status voor vluchtelingen of voor personen die in aanmerking komen voor subsidiaire bescherming, en voor de inhoud van de verleende bescherming (herschikking), PbEU 2011, L 337/9. 
aan vervolging te ontkomen (de zogenoemde 'discretie'). Over de zaken $X, Y$ en $Z$ (en de voorafgaande prejudiciële verwijzing) is al het nodige geschreven. ${ }^{3}$

Voordat het Hof van Justitie de uitspraak inzake $X, Y$ en $Z$ deed, was door de Afdeling (in maart 2013) al een prejudiciële vraag aan het Hof van Justitie gesteld over het beoordelen van asielverzoeken van personen die vanwege hun homoseksualiteit voor vervolging vrezen. ${ }^{4}$ Het betrof de asielverzoeken van de mannen $A, B$ en $C$; deze verzoeken berustten op de stelling dat zij vanwege hun seksuele gerichtheid voor vervolging vreesden. A., uit Gambia, had een tweede asielverzoek ingediend en verklaarde zich bereid een test te ondergaan waaruit zijn homoseksualiteit zou blijken. De Afghaan B betoogde uitsluitend dat hij homoseksueel was. C, uit Uganda, had eerst een asielverzoek op andere gronden ingediend en pas in een tweede asielaanvraag gesteld dat hij voor vervolging vreesde vanwege zijn homoseksuele gerichtheid. Bij die aanvraag had hij een film overgelegd waarin hij seksuele handelingen met een andere man verrichtte. De staatssecretaris wees deze drie verzoeken af omdat hij de door de mannen gestelde homoseksualiteit niet geloofwaardig achtte.

In de zaken $A, B$ en $C$ stelde de $A B R v S$ de volgende prejudiciële vraag aan het Hof van Justitie:

'Welke grenzen stellen artikel 4 van de richtlijn 2004/83/EG (...), en de inhoud van de verleende bescherming, en het Handvest (...), in het bijzonder de artikelen 3 en 7 daarvan, aan de wijze van beoordelen van de geloofwaardigheid van een gestelde seksuele gerichtheid en verschillen die grenzen van de grenzen die gelden voor de beoordeling van de geloofwaardigheid van de andere gronden van vervolging en, zo ja, in welk opzicht?'

Op 2 december 2014 beantwoordde het Hof van Justitie deze vraag over de toets van de geloofwaardigheid van asielrelazen van homoseksuele asielzoekers (HvJ 2 december 2014, gevoegde zaken C-148/13, C-149/13

3. Zonder de pretentie van volledigheid een kort overzicht; H. Battjes, 'Asielverzoeken van homoseksuelen: $X, Y$ en $Z$ tegen de Minister voor immigratie en asiel', A\&MR 2013, nr. 10, p. 504-512; B. Vermeulen en A. Woltjer, 'Wat te geloven? Over discretie, zelfinterpretatie en vervolging wegens godsdienst en seksuele gerichtheid', in: K. Groenendijk e.a. (red.), Issues that Matter. Mensenrechten, minderheden en migranten. Liber amicorum voor Prof. mr. R. Fernhout, Nijmegen: Wolf Legal Publishers 2013, p. 31-43; annotaties door M. den Heijer, EHRC 2014/8, S. Jansen, JV 2014/48 en A. Terlouw, RV 2013, 9. Tevens verscheen een tweeluik van de hand van S. Jansen en T. Spijkerboer, 'Homoseksuele en transgender asielzoekers, discretie en strafbaarstelling. De draaideurkast', A\&MR 2012, nr. 7, p. 320-329, en 'Homoseksuele en transgender asielzoekers, laat uit de kast komen en geloofwaardigheid, Say it loud - en vlug een beetje', A\&MR 2012, nr. 9, p. 456-463.

4. JV 2013/159

5. Zie hierover ook de opinie van R. Bruin, 'Altijd voorzichtig. Over het interviewen van homoseksuele asielzoekers', A\&MR 2014, nr. 1, p. 25-30. en $\mathrm{C}-150 / 13, A, B$ en $C) .{ }^{5}$ In deze bijdrage zal met name worden ingegaan op deze uitspraak. ${ }^{6}$

\section{Bespreking van het arrest van het Hof van Justitie}

Beantwoording van de prejudiciële vraag

Het Hof van Justitie heeft ervoor gekozen de beantwoording van de vraag van de Raad van State in vier onderdelen uiteen te laten vallen. Deze vier onderdelen worden hieronder besproken. Het Hof van Justitie overweegt (punt 53) dat de wijze waarop de bevoegde autoriteiten de tot staving van asielverzoeken overgelegde verklaringen en het daartoe overgelegde bewijsmateriaal beoordelen, in overeenstemming moet zijn met de Definitie- en Procedurerichtlijn en met de door het Handvest van de grondrechten van de EU (hierna: Handvest) gewaarborgde grondrechten, zoals het in artikel 1 van het Handvest vervatte recht op eerbiediging van de menselijke waardigheid en het in artikel 7 ervan gewaarborgde recht op eerbiediging van het privéleven en van het familie- en gezinsleven. De Definitierichtlijn 2004/83/ $\mathrm{EG}^{7}$ en de Procedurerichtlijn 2005/85/EG ${ }^{8}$ bevatten minimumnormen voor, respectievelijk, de erkenning van derdelanders als vluchteling en de procedures voor het onderzoek van asielaanvragen, en geven nadere invulling aan de rechten van asielzoekers. Het Hof van Justitie neemt niet het standpunt in dat de enkele verklaringen van de asielzoeker over zijn seksuele gerichtheid als vaststaand feit moeten worden overgenomen, maar vindt dat deze verklaringen uitgangspunt moeten zijn voor de verdere beoordeling (punt 49).

\section{- Stereotiepe opvattingen}

De eerste alinea van het antwoord van het Hof van Justitie luidt:

'Artikel 4, lid 3, sub c, van richtlijn 2004/83/EG (...), en artikel 13, lid 3, sub a, van richtlijn 2005/85/

EG (...), moeten in die zin worden uitgelegd dat zij zich ertegen verzetten dat, in het kader van het onderzoek door de bevoegde nationale autoriteiten, handelend onder toezicht van de rechter, van de feiten en omstandigheden betreffende de gestelde seksuele gerichtheid van een asielzoeker wiens verzoek is gebaseerd op vrees voor vervolging wegens die gerichtheid, de verklaringen en het bewijsmateriaal

6. Zie voor commentaar op deze uitspraak: Uitspraak van de Maand, A. Terlouw, 'Seksuele gerichtheid onderdeel van menselijke waardigheid', A\&MR 2014, nr. 10, p. 446-449; JV 2015/3, m.nt. L. Middelkoop; H. Battjes, 'Belangrijke uitspraak: grens aan intieme vragen homoseksuele asielzoeker', verblijfblog.nl; S. Chelvan, 'C-148/13, C-149/13 and C-150/13, A, B and C v Staatssecretaris van Veiligheid en Justitie: Stop Filming and Start Listening - a judicial black list for gay asylum claims', europeanlawblog.eu.

7. Ook wel aangeduid als Erkenningsrichtlijn of Kwalificatierichtlijn.

8. Richtlijn $2005 / 85 /$ EG van 1 december 2005 betreffende minimumnormen voor de procedures in de lidstaten voor de toekenning of intrekking van de vluchtelingenstatus, PbEU 2005, L 326/13. 
tot staving van diens verzoek door die autoriteiten worden beoordeeld middels ondervragingen louter op basis van stereotiepe opvattingen over homoseksuelen.'

Geloofwaardigheidsbeoordeling bij de beoordeling van asielaanvragen is bijzonder moeilijk. De asielzoeker zelf levert, door middel van het vertellen van zijn asielrelaas, de belangrijkste informatie. Bij de beantwoording van deze eerste vraag wijst het Hof van Justitie erop dat naast de verklaringen van de asielzoeker alle omstandigheden van het geval in aanmerking moeten worden genomen. De zelfverklaarde seksuele gerichtheid is uitgangspunt voor een verdere beoordeling (par. 50). De UN High Commissioner for Refugees (hierna: UNHCR) heeft ook benadrukt dat 'self identification should be taken as an indication to the individual's sexual orientation'. ${ }^{9}$

De beoordeling van het bestaan van vervolging vanwege het behoren tot een bepaalde sociale groep (vanwege seksuele gerichtheid), waarin verklaringen en het bewijsmateriaal worden beoordeeld door middel van ondervragingen louter op basis van stereotiepe opvattingen over homoseksuelen is niet toegestaan. Gebruik van stereotyperingen wordt dus wel toegestaan. Dit is problematisch. Geloofwaardigheid van een gestelde seksuele gerichtheid vindt vaak plaats op basis van stereotypen, zo blijkt uit onderzoek. ${ }^{10}$ Verschillende vormen van stereotypering worden aangehaald, zoals bijvoorbeeld dat homoseksuele mannen niet zo houden van sport, maar wel van de kleur roze. Het Hof van Justitie beperkt zich bij de beantwoording van deze vraag tot vragen naar kennis van homorechtenbewegingen, en richt zich niet op het gebruik van stereotypen in de meest ruime zin. Het Hof van Justitie oordeelt dat vragen naar homobewegingen wel nuttig kunnen zijn, maar niet voldoende zijn voor een individuele geloofwaardigheidsbeoordeling.

- $\quad$ Praktische invulling seksuele gerichtheid

Het tweede antwoord van het Hof van Justitie luidt:

'Artikel 4 van richtlijn 2004/83, gelezen in het licht van artikel 7 van het Handvest van de grondrechten van de Europese Unie, moet in die zin worden uitgelegd dat het zich ertegen verzet dat de bevoegde nationale autoriteiten in het kader van dat onderzoek een asielzoeker gedetailleerd ondervragen over de wijze waarop hij praktisch invulling geeft aan zijn seksuele gerichtheid.'

Ter vaststelling van de geloofwaardigheid van het asielrelaas, wanneer vervolging op basis van seksuele gerichtheid aan de orde is, moeten aan de asielzoeker vragen worden gesteld over zijn seksuele gerichtheid. Dit is

9. UNHCR Guidelines No. 9 on Sexual Orientation and Gender Identity Claims, May 2013, <www.refworld.org>

10. S. Jansen, 'Herken de homo. Over het beoordelen van de geloofwaardigheid van seksuele gerichtheid in asielzaken', Justitiële Verkenningen 2013, nr. 5. alleen al nodig voor de vaststelling dat sprake is van een dergelijke gerichtheid. Het Hof van Justitie oordeelt dat gedetailleerd vragen naar de praktische invulling van de homoseksuele gerichtheid niet is toegestaan. Algemene vragen zijn dus wel toegestaan. Net als bij de beantwoording van vraag 1 (niet louter op basis van stereotypering) dringt zich bij de beantwoording van deze vraag (geen gedetailleerde ondervraging) de vraag op wat hier nu precies aan handvatten worden geboden voor zowel de staatssecretaris, als voor de nationale rechter. Het wordt steeds duidelijker wat allemaal niet mag...

\section{- Homoseksuele handelingen, tests en video's}

De beantwoording van de derde vraag is:

'Artikel 4 van richtlijn 2004/83, gelezen in het licht van artikel 1 van het Handvest van de grondrechten van de Europese Unie, moet in die zin worden uitgelegd dat het zich ertegen verzet dat die autoriteiten in het kader van dat onderzoek bewijsmateriaal aanvaarden als het demonstratief verrichten van homoseksuele handelingen door de betrokken asielzoeker, het ondergaan van "tests" om zijn homoseksualiteit te bewijzen of het overleggen van video-opnamen van dergelijke handelingen.'

Het Hof van Justitie verwijst naar artikel 1 van het Handvest met betrekking tot de menselijke waardigheid. ${ }^{11}$ Het Hof van Justitie verricht geen expliciete toets aan deze bepaling, maar legt de richtlijn uit in het licht van artikel 1 van hetHandvest. ${ }^{12}$ Het Hof van Justitie maakt hiermee duidelijk dat seksuele gerichtheid onderdeel is van de menselijke waardigheid zoals beschermd door artikel 1 van het Handvest. ${ }^{13}$

Het Hof van Justitie geeft hiermee uitdrukkelijk geen limitatieve opsomming van bewijsmateriaal dat niet mag worden aanvaard. Het noemt hier drie concrete vormen van bewijs die zijn verboden (demonstratief verrichten van homoseksuele handelingen; het ondergaan van 'tests'; het overleggen van video-opnamen van homoseksuele handelingen).

In veel landen - ook in Nederland - is bij het doen van een aanvraag, zoals een asielaanvraag, een aanvrager vrij in de keuze van bewijsmateriaal om een aanvraag te onderbouwen. De overheid dient, onder meer met het oog op het vereiste van de zorgvuldige voorbereiding (art. 3:2 Awb) en de plicht tot toereikende motivering (art. 3:46 Awb), acht te slaan op aangeleverd bewijs.

11. Vanaf 2004 wordt in arresten van het Hof van Justitie verwezen naar de bescherming van de menselijke waardigheid, zie HvJ 14 oktober 2014, zaak C-36/02, Omega Spielhallen, ECLI:EU:C:2004:614. In asielgerelateerde zaken is de menselijke waardigheid uit art. 1 Grondrechtenhandvest genoemd in HvJ 27 september 2012, zaak C-179/11, Cimade \& Gisti, ECLI:EU:C:2012:594 en HvJ 27 februari 2014, zaak C-79/13, Saciri e.a., ECLI:EU:C:2014:103.

12. Zie over art. 1 Grondrechtenhandvest: K. Lenaerts, 'Exploring the limits of the EU Charter of fundamental rights', European Constitutional Law Review 2012, p. 375-403.

13. Dit is een betrekkelijk nieuw gegeven, zie het interview met antropoloog P. Geschiere, 'Je kunt niet zeggen: homoseksualiteit is dit of dat', A\&MR 2013, nr. 9, p. 482-485. 
Advocaat-generaal Sharpston besteedt in haar conclusie $^{14}$ aandacht aan dit punt van spanning (par. 55 e.v.). $\mathrm{Zij}$ betoogt dat 'de erkenningsrichtlijn geen bepalingen kent met betrekking tot de bewijsmiddelen die mogen worden aangevoerd tot staving van een verzoek om toekenning van de vluchtelingenstatus'. Het Unierecht stelt, aldus de advocaat-generaal, wel grenzen aan de vrijheid van de lidstaten om ter beoordeling van de geloofwaardigheid praktijken of methoden te kiezen.

Bewijs moet worden verzameld op een wijze die de grondrechten van de verzoeker eerbiedigt. Methodes die vernederend zijn of in strijd zijn met de menselijke waardigheid, zoals pseudomedische tests of het beoordelen door te verwijzen naar stereotypes, schenden zowel de Definitierichtlijn als het grondrechtenhandvest.

\section{- Tmeede asielaanvraag}

Het vierde deel van het antwoord luidt als volgt:

'Artikel 4, lid 3, van richtlijn 2004/83 en artikel 13, lid 3, sub a, van richtlijn 2005/85 moeten in die zin worden uitgelegd dat zij zich ertegen verzetten dat de bevoegde nationale autoriteiten in het kader van dat onderzoek tot de slotsom komen dat de verklaringen van de betrokken asielzoeker niet geloofwaardig zijn louter omdat deze zijn gestelde seksuele gerichtheid niet had aangevoerd bij de eerste gelegenheid die hem werd geboden om de vervolgingsgronden toe te lichten.'

Het vierde deel van het antwoord van het Hof van Justitie betreft de vraag welke betekenis mag worden toegekend aan het niet direct aanvoeren van de homoseksuele gerichtheid. Bij de beoordeling van de geloofwaardigheid mag dus wel degelijk een rol spelen dat de asielzoeker niet direct bij de eerste mogelijkheid over zijn seksuele gerichtheid en zijn vrees voor vervolging op grond daarvan verklaart, maar dat mag niet de enige reden zijn voor afwijzing van het verzoek op grond van ongeloofwaardigheid. Er moeten dus andere omstandigheden zijn die de verklaringen ongeloofwaardig maken.

In de Nederlandse praktijk levert het in een tweede of volgende asielaanvraag aanvoeren van homoseksualiteit een procedureel probleem op. ${ }^{15} \mathrm{Op}$ grond van artikel 4:6 Awb kan het bestuursorgaan, indien geen nieuw gebleken feiten of veranderde omstandigheden worden vermeld, zonder toepassing te geven aan artikel 4:5 Awb, de aanvraag afwijzen onder verwijzing naar de eerdere afwijzende beschikking. Dit geldt wel alleen indien het een beschikking van gelijke strekking betreft (met hetzelfde doel en dezelfde geldigheidsduur). ${ }^{16}$ De Afdeling geeft een strikte invulling aan het begrip 'nieuw gebleken feiten of veranderde omstandigheden'. Hieronder moeten worden begrepen feiten of omstandigheden die

14. Conclusie van A-G Sharpston 17 juli 2014, gevoegde zaken C-148/13 tot en met C-150/13, A, B en C.

15. Zie hierover uitgebreid S. Jansen en T. Spijkerboer, 'Homoseksuele en transgender asielzoekers, laat uit de kast komen en geloofwaardigheid, Say it loud - en vlug een beetje', A\&MR 2012, nr. 9, p. 456-463.

16. Zie ook de noot van Zwaan bij ABRvS 29 augustus 2014, nr. 201400245/1/V1, JV 2014/390. na het eerdere besluit zijn voorgevallen of die niet vóór dat besluit konden en derhalve behoorden te worden aangevoerd, alsmede bewijsstukken van reeds eerder gestelde feiten of omstandigheden, die niet vóór het nemen van het eerdere besluit konden en derhalve behoorden te worden overgelegd. In het asielrecht is een uitzondering mogelijk op de toepassing van artikel 4:6 Awb, de zogenoemde Bahaddar-toets. ${ }^{17}$ Van tegenwerping van artikel 4:6 Awb kan geen sprake zijn indien bijzondere, individuele omstandigheden noodzaken een nationaalrechtelijke procedureregel niet toe te passen omdat stellingen van de vreemdeling onmiskenbaar tot het oordeel leiden dat uitzetting in strijd met het refoulementverbod ${ }^{18}$ zou zijn.

Verschillen tussen conclusie advocaat-generaal en arrest

Op 17 juli 2014 bracht advocaat-generaal Sharpston ${ }^{19}$ haar conclusie uit. Op een aantal punten wijkt het arrest af van haar conclusie. Net zoals in de zaak $X, Y, Z$ is in de conclusie van de advocaat-generaal meer andacht voor de uitleg van internationaal recht, aandacht voor soft law, en de standpunten van UNHCR. ${ }^{20}$ Haar formuleringen van wat wel en niet mag bij een geloofwaardigheidsbeoordeling zijn 'strenger' dan hetgeen uiteindelijk in de uitspraak is terug te vinden. Een aantal voorbeelden.

Asielzoekers zouden de mogelijkheid moeten krijgen om voor de vaststelling van een definitief besluit te reageren op twijfels over hun geloofwaardigheid (par. 92), aldus Sharpston. Het Hof van Justitie zegt niets over de mogelijkheid die de asielzoeker moet worden geboden om twijfels over de geloofwaardigheid te weerleggen.

Het Hof van Justitie laat in het midden welk bewijsmateriaal denkbaar is, en geeft aan welk bewijsmateriaal in elk geval niet mag worden verlangd en geaccepteerd. Sharpston was van mening dat homoseksualiteit niet kan worden bewezen (par. 69). Zij concludeert dat homoseksualiteit geen medische aandoening is en op basis van medische onderzoeken kan een seksuele gerichtheid niet worden vastgesteld. Een seksuele gerichtheid kan niet feitelijk worden bewezen. ${ }^{21}$ Medische testen en indringende ondervragingen of het verschaffen van expliciet bewijs berusten op stereotiepe veronderstellingen over

17. Genoemd naar de zaak EHRM 19 februari 1998, appl. no. 25894/94, JV 1998/45.

18. Het verbod van refoulement verbiedt de terugzending van vreemdelingen naar hun land van herkomst indien zij daar vervolging, foltering, onmenselijke, vernederende of wrede behandeling te vrezen hebben. Refoulementverboden zijn te o.a. te vinden in art. 33 Vluchtelingenverdrag, art. 3 Anti-folterverdrag, art. 3 EVRM, art.7 IVBPR, en ook in een aantal EU-richtlijnen, zoals art. 21 van de in het arrest genoemde Richtlijn 2004/83/EG.

19. Conclusie van A-G Sharpston van 17 juli 2014, gevoegde zaken C-148/13 tot en met C-150/13, A, B en C.

20. Zie UNHCR, Written Observations of the United Nations High Commissioner for Refugees in the cases of A and Others (C-148/13, 149/13 and 150/13), 21 augustus 2013, C-148/13, C-149/13 \& C-150/13, $<$ www.refworld.org $>$.

21. Hier wordt verschillend over gedacht. De neurobioloog Swaab zegt dat je homoseksuele gerichtheid aan de hersenen kunt zien, aldus antropoloog P. Geschiere, 'Je kunt niet zeggen: homoseksualiteit is dit of dat', A\&MR 2013, nr. 9, p. 484 
homoseksueel gedrag en druisen in tegen de door de Definitierichtlijn vereiste individuele behandeling. $\mathrm{Zij}$ schenden de grondrechten van asielzoekers, zelfs als zij met deze methodes instemmen. $Z$ ij verwijst daarbij naar artikel 52 lid 1 Grondrechtenhandvest. ${ }^{22}$

Advocaat-generaal Sharpston schrijft dat indringende ondervragingen ('intrusive questioning') niet mogen, het Hof van Justitie heeft het over gedetailleerde ondervragingen ('detailed questioning'). ${ }^{23}$

De advocaat-generaal en het Hof van Justitie verschillen ook van mening over de bewijslastverdeling bij de vaststelling van de geloofwaardigheid. Hierbij speelt de zogenoemde samenwerkingsplicht van artikel 4 Definitierichtlijn een belangrijke rol. Deze samenwerkingsplicht $^{24}$ wordt door Sharpston veel zwaarder aangezet dan door het Hof van Justitie (par. 73 Conclusie):

'De in artikel 4, lid 1, van de erkenningsrichtlijn bedoelde samenwerking is geen rechtszaak. Het is voor de verzoeker een mogelijkheid om zijn relaas te doen en zijn bewijs over te leggen en voor de bevoegde autoriteiten om informatie te verzamelen, de verzoeker te zien en te horen, zijn gedrag te beoordelen en de aannemelijkheid en samenhang van dat relaas te onderzoeken. Het woord "samenwerking" houdt in dat beide partijen streven naar de verwezenlijking van een gemeenschappelijk doel.'

\section{Verschillen tussen de taalversies}

Een aantal auteurs heeft reeds gewezen op mogelijke verschillen tussen de taalversies van het arrest. ${ }^{25}$ In de beantwoording van vraag 1 komt het Hof van Justitie tot de conclusie dat die verklaringen en het bewijsmateriaal niet mogen worden beoordeeld door ondervragingen 'louter' ('only' in de Engelse taalversie) op basis van stereotiepe opvattingen over homoseksuelen. Stereotiepe opvattingen mogen bij de ondervragingen blijkbaar wel een rol spelen maar de ondervragingen mogen niet alleen (louter) daarop zijn gebaseerd. Door het gebruik van het woord louter blijft de mogelijkheid open in combinatie met iets anders gebruik te maken van stereotypen.

Bij de beantwoording van vraag 2 is er ook verschil tussen de Engelse, Duitse, Franse en de Nederlandse vertaling. In het Nederlands verbiedt het Hof van Justitie

22. Art. 52 lid 1 Handvest luidt: 'Beperkingen op de uitoefening van de in dit handvest erkende rechten en vrijheden moeten bij wet worden gesteld en de wezenlijke inhoud van die rechten en vrijheden eerbiedigen. Met inachtneming van het evenredigheidsbeginsel kunnen alleen beperkingen worden gesteld indien zij noodzakelijk zijn en daadwerkelijk aan door de Unie erkende doelstellingen van algemeen belang of aan de eisen van de bescherming van de rechten en vrijheden van anderen beantwoorden.'

23. Zie hierover verder A. Terlouw in haar bespreking van deze uitspraak in A\&MR 2014, nr. 10.

24. Die ook nader door het Hof van Justitie is vormgegeven in HvJ 22 november 2012, zaak C-277/11 (55), M.M., JV 2013/8, m.nt. P. van Reenen; zie ook R. Severijns, "“ $M$ tegen lerland" noopt niet tot aanpassing Nederlandse praktijk', A\&MR 2013, nr. 2

25. Zie hierover uitgebreid A. Terlouw in haar bespreking van deze uitspraak in A\&MR 2014, nr. 10; L. Middelkoop wijst hier ook op in zijn noot bij het arrest $A, B$ en $C$ in $J V 2015 / 3$. gedetailleerde vragen over de seksuele gerichtheid. In het Engels staat er dat de asielzoeker niet gedetailleerd mag worden bevraagd over 'sexual practice', de Duitstalige versie noemt 'sexuellen Praktiken', en de Franse uitspraak 'pratiques sexuelles'. Sexual practice en seksuele gerichtheid zijn niet identiek.

Bij de beantwoording van vraag 4 is opnieuw sprake van het gebruik van het woord 'louter'. Maar waar bij de beantwoording van vraag 1 de Engels pendant 'only' was, is hier sprake van een vertaling van 'merely'. Bij de beoordeling van de geloofwaardigheid mag een rol spelen dat de asielzoeker niet de eerst mogelijke gelegenheid heeft aangegrepen om over zijn seksuele gerichtheid te verklaren, maar dat mag niet de enige reden zijn voor afwijzing van het verzoek op grond van ongeloofwaardigheid.

\section{En wat vindt het Hof van Justitie in Straatsburg} daar dan van...

Het Europees Hof voor de Rechten van de Mens (hierna: EHRM of Hof in Straatsburg) heeft in een groot aantal uitspraken ook invulling gegeven aan mogelijke gevolgen van het zijn van homoseksueel en mogelijke schendingen van bijvoorbeeld artikel 3 EVRM (onmenselijke behandeling), artikel 8 EVRM (familieleven, privéleven) en artikel 14 EVRM. ${ }^{26}$

Ook over het eerdergenoemde element 'zelfidentificatie' heeft het Hof in Straatsburg geoordeeld. In de zaak $V a n$ Kück/Duitsland uit $2003^{27}$ besliste het EHRM dat seksuele zelfidentificatie tot de kern van het privéleven hoort en dat iemands eigen identificatie niet door de overheid in twijfel mag worden getrokken. ${ }^{28}$ Het EHRM achtte bij de beoordeling van deze zaak met name het beginsel van persoonlijke autonomie en menselijke waardigheid van belang.

In het kader van de asielprocedure blijkt zelfidentificatie onvoldoende. Het Hof van Justitie neemt de verklaring van de asielzoeker over zijn seksuele gerichtheid, zijn zelfidentificatie, wel als het vertrekpunt bij een geloofwaardigheidsbeoordeling. Maar alleen zelfidentificatie is - mede door toepassing van artikel 4 Definitierichtlijn onvoldoende. Advocaat-generaal Sharpston had in haar conclusie wel geconcludeerd dat zelfdefinitie van seksuele gerichtheid (onder verwijzing naar Van Kück) onder de werking van artikel 7 Grondrechtenhandvest valt. Het Hof van Justitie oordeelt dat (par. 52):

'(...) dat het weliswaar aan de asielzoeker staat om te wijzen op deze gerichtheid, die een element van zijn persoonlijke levenssfeer vormt, doch dat verzoeken om toekenning van de vluchtelingenstatus die zijn gebaseerd op vrees voor vervolging wegens die gerichtheid, net als verzoeken op basis van andere gronden van vervolging, voorwerp van een beoorde-

26. Zie bijvoorbeeld EHRM 19 februari 2013, appl.nr. 19010/07, X. e.a./ Oostenrijk.

27. EHRM 12 juni 2003, appl.nr. 35968/97

28. Zie hierover ook L. Middelkoop in zijn noot bij het arrest $A, B$ en $C$ in JV 2015/3. 
ling in de zin van artikel 4 van die richtlijn kunnen vormen.'

\section{Wat betekent dit arrest voor $A$, $B$ en $C$ ?}

De enkele stelling van B dat hij homoseksueel is, is niet voldoende (zie par. 49 arrest). Deze stelling is een mededeling die nader geverifieerd mag worden. B's verhaal werd te summier en te vaag bevonden. $C$ had pas in zijn tweede asielaanvraag een beroep op zijn homoseksuele gerichtheid gedaan. Dat mag volgens het Hof van Justitie niet de enige reden zijn om zijn verzoek af te wijzen. Maar of zijn relaas daarmee voldoende geloofwaardig zal worden bevonden is de vraag. De film met zijn seksuele verrichtingen zal niet als bewijs mogen worden aanvaard. Ook $A$ had een tweede asielaanvraag ingediend met een bewijsaanbod van medisch onderzoek. Een tweede asielaanvraag moet kunnen, maar medisch onderzoek zal toch onder onaanvaardbaar (en onmogelijk) bewijs vallen.

Een latere verklaring van de asielzoeker dat hij homoseksueel is, kan niet terzijde worden geschoven enkel omdat de asielzoeker dit al eerder had kunnen verklaren. In de Vreemdelingencirculaire staat dit nu ook al:

'Indien de vreemdeling pas tijdens een tweede of opvolgende asielaanvraag aangeeft dat hij homoseksueel is, en deze informatie wordt geloofwaardig geacht, dan wordt de vreemdeling niet tegengeworpen dat hij niet tijdens een voorgaande procedure gewag heeft gemaakt van zijn homoseksuele geaardheid. ${ }^{29}$

De vraag blijft dus, hoe nu verder? ${ }^{30}$

\section{Conclusie}

Het is door dit arrest voornamelijk duidelijk geworden wat níet mag als het gaat om de vaststelling van de geloofwaardigheid van homoseksuele asielzoekers. Maar het blijft onduidelijk wat dan wél mag. Wanneer is bij de bevraging van een asielzoeker sprake van het gebruik van zogenoemde 'useful stereotypes'? Mogen niet gedetailleerde vragen over het seksleven wel? Welke gevolgen heeft het niet direct noemen van homoseksualiteit voor de geloofwaardigheid?

De uiteindelijke toets ligt bij de nationale rechters, waarbij de eerbieding van artikel 1 EU Grondrechtenhandvest (menselijke waardigheid) richtinggevend is.
Maar aangezien er nog vrijwel geen arresten zijn over de precieze invulling van artikel 1 Handvest heeft zowel de staatssecretaris bij het maken van een beschikking als de nationale rechter bij het toetsen van die beschikking een lastige taak.

29. Vreemdelingencirculaire 2000 C14/4.1.

30. Ondertussen worden voorlopige voorzieningen door rechtbanken toegewezen omdat het opportuun geacht wordt de uitspraak van de Afdeling inzake $A, B$ en $C$ - waarin de prejudiciële vragen zijn gesteld - af te wachten, omdat die uitspraak mogelijk ook relevant is voor de beoordeling van de ingestelde beroepen. Zie o.a. recent Rb. Zwolle 13 januari 2015, AWB 14/28571. 